une revue Gallia

Rhône-Alpes | 2008

\title{
Metz-Tessy
}

Les Prés-Falquet

\section{Franck Gabayet}

\section{(2) OpenEdition}

12 Journals

Édition électronique

URL : http://journals.openedition.org/adlfi/1493

ISSN : 2114-0502

Éditeur

Ministère de la culture

Référence électronique

Franck Gabayet, « Metz-Tessy », ADLFI. Archéologie de la France - Informations [En ligne], Rhône-Alpes, mis en ligne le 01 mars 2008, consulté le 30 avril 2019. URL : http://journals.openedition.org/ adlfi/1493

Ce document a été généré automatiquement le 30 avril 2019.

(c) Ministère de la Culture et de la Communication, CNRS 


\title{
Metz-Tessy
}

\author{
Les Prés-Falquet
}

Franck Gabayet

\section{Identifiant de l'opération archéologique : 9907}

Date de l'opération : 2008 (EX)

1 En préalable à la construction de plusieurs immeubles dans un secteur potentiellement susceptible de receler des vestiges antiques, a été prescrit un diagnostic archéologique. Le terrain était anciennement dévolu à des activités agricoles.

2 Adossée au bois des Machurettes $(694 \mathrm{~m})$, la commune se présente comme un vaste amphithéâtre entouré d'une ceinture verte, largement ouvert au sud sur un paysage de montagnes, où les éléments naturels sont fortement visibles. Elle est en outre traversée par le Viéran, jusqu'aux îles du Fier $(428 \mathrm{~m})$. Au niveau géologique, la commune est essentiellement composée d'une plaine recouverte de dépôts d'alluvions d'origine lacustre qui constituent une formation d'une superficie importante. Selon P. Broise, comme sa voisine Épagny, la commune de Metz-Tessy serait quadrillée par un ancien parcellaire fossile. D'après $\mathrm{C}$. Marteau, qui y avait naguère identifié des tuiles à rebords, le toponyme Tessy serait issu d'un domaine antique (Tessiacum).Des tegulaeet des poteries ont été trouvées en 1972, au Longeray, et en 1975 et 1976, à Tessy, au pré de la Tour dans les fondations de quatre maisons construites en bordure du chemin vicinal $n^{\circ} 2$ (Broise, 1984, p. 253).

De fait, un examen rapide des labours, dans la partie nord-ouest des parcelles concernées par l'opération de diagnostic, au lieu-dit «Prés-Falquet », a livré de nouvelles tegulae, souvent roulées, il est vrai.

4 L'intervention a surtout été l'occasion de repérer une petite nécropole antique qui se présente sous la forme de fosses charbonneuses. L'analyse de la stratigraphie montre que les tombes sont mal conservées, sur une hauteur de 0,20 $\mathrm{m}$ tout au plus, sans doute victimes du colluvionnement généré par le dénivelé. La partie supérieure des creusements est donc absente. Toutefois, sans vouloir avancer des hypothèses trop 
hardies, il est probable que la nécropole comprenne à la fois des tombes bûcher et des dépôts de crémation. Comme souvent, aucune trace de bûcher collectif n'a été identifiée. Le mobilier se limite pour l'essentiel à des dépôts céramiques, avec une forte majorité de cruches, associés à de rares fragments de verre. Quelques clous en bronze, ainsi que de petits clous de chaussure sont également présents. Une partie du mobilier a subi le bûcher, en même temps que les défunts, tandis que le reste des objets correspond à des dépôts secondaires déposés non brûlés dans la tombe. En matière de datation, les données sont lacunaires, mais permettent de placer cet ensemble entre le milieu du $1^{\mathrm{er}} \mathrm{s}$. et la deuxième moitié du $\mathrm{II}^{\mathrm{e}} \mathrm{s}$. voire le début du $\mathrm{III}^{\mathrm{e}} \mathrm{s}$.

En l'état, l'ensemble funéraire est connu par une dizaine d'individus, avec cette réserve que certaines des fosses, mal identifiées pourraient de fait correspondre à plusieurs dépôts. Par ailleurs par le jeu des sondages, il reste une surface d'environ $800 \mathrm{~m}^{2}$ non étudiée et le nombre des tombes pourrait être multiplié par six, sans même considérer le potentiel de la parcelle adjacente, côté sud, qui échappe à l'emprise de fouille.

6 La localisation de la zone sépulcrale et le nombre limité des sujets laissent supposer que la nécropole relevait d'un domaine dont aucune trace n'est aujourd'hui repérée, sinon sous la forme de tuiles à rebords, dont des fragments ont été observés dans les labours, en particulier à environ $150 \mathrm{~m}$ au nord-ouest des tombes. On serait dès lors tenté de d'envisager la présence de ce probable habitat quelque part sur la partie haute de la colline, à la limite de l'emprise diagnostiquée.

\section{INDEX}

Thèmes : clou, nécropole à incinération, verre

Index chronologique : Ier siècle apr. J.-C., IIe siècle apr. J.-C.

Index géographique : Rhône-Alpes, Haute-Savoie (74), Metz-Tessy

operation Expertise (EX)

\section{AUTEUR}

\section{FRANCK GABAYET}

INRAP 